\title{
Synthesis of $N$-Heteroaroyl Aminosaccharide Derivatives as Fibroblast Growth Factor 2 Signaling Modulators
}

\author{
Jin Dong, ${ }^{a}$ Shuowei YaO, ${ }^{a}$ Xiaodong Zhou, ${ }^{b}$ Lijuan Zhang, ${ }^{b}$ and Yungen $\mathrm{XU}^{*, a}$ \\ ${ }^{a}$ Department of Medicinal Chemistry, China Pharmaceutical University; 24 Tongjiaxiang, Nanjing 210009, China: and \\ ${ }^{b}$ Department of Pathology and Immunology, Washington University School of Medicine; 660 S. Euclid Avenue, St. Louis, \\ MO 63110, U.S.A. Received December 15, 2009; accepted May 4, 2010; published online June 10, 2010
}

Fibroblast growth factor 2 (FGF2) signaling plays an important role in angiogenesis. Heparin/heparan sulfate (HS) is required for FGF2 signaling but heparin mimics either promotes or inhibits FGF2 signaling. To take advantage such properties of heparin mimics, a series of $N$-heteroaroyl aminosaccharide derivatives were designed and synthesized as FGF2 signaling modulators. The bioactivity was determined in a FGF2 and heparindependent cell proliferation assay using FGFR1c expressing BaF3 cells. We found that most of the compounds inhibited heparin- and FGF2-dependent BaF3 cell proliferation while three compounds promoted the cell proliferation. These results suggest that the small molecular heparin mimics approach might be useful in developing novel anti-angiogenic agents.

Key words fibroblast growth factor 2; fibroblast growth factor receptor; angiogenesis; $N$-heteroaroyl aminosaccharide; heparin mimic

Canonical fibroblast growth factor (FGF) signals are not only essential in mammalian embryogenesis, but also play important roles in tissue repair, tumor biology, ${ }^{1,2)}$ aging, ${ }^{3)}$ and diabetic control $^{4}$ throughout adult life. FGF2, the most extensively studied member of the FGF family, exerts its biological activities including angiogenesis through binding to high-affinity tyrosine kinase FGF receptors ${ }^{5)}$ and heparin/heparan sulfate (HS). Heparin/HS is required to form a ternary complex with FGF and FGFR to stabilize and activate FGF signaling for a long enough period of time to elicit a specific response. ${ }^{6}$ ) It has been demonstrated that the heparin sequences that bind to FGF and FGFR are different from that of required for ternary complex formation ${ }^{7)}$ and different heparin sequences either inhibits or promotes FGF signaling. ${ }^{8)}$ Therefore, it is possible to develop heparin mimics-based FGF signaling modulators by taking advantage of complex sugar structures.

Heparin and the structurally related heparan sulfate (HS) are glycosaminoglycans (GAGs) constituted by repeating disaccharide units of $\alpha$-D-glucosamine (GlcNAc or D-glucosamine $N$-sulfate $\left.\left(\mathrm{GlcNSO}_{3}\right)\right)$ and an uronic acid $(\beta$-D-glucuronic acid (GlcA) or $\alpha$-L-iduronic acid (IdoA)). Clinical trials have revealed that treatment with various low-molecular-weight heparins improves the survival time of tumor patients. The anti-angiogenic effects of these heparin derivatives likely play a central role in their anti-tumor activities. ${ }^{9}$ Preclinical studies have demonstrated that heparin/HS are able to modulate the activities of various angiogenic growth factors, most of which are heparin-binding proteins, such as FGF and vascular endothelial growth factor (VEGF). ${ }^{10)} \mathrm{PI}-$ 88 , a mixture of highly sulfated, monophosphorylated mannose oligosaccharides, derived from the extracellular phosphomannan of the yeast Pichia holstii which inhibits tumor angiogenesis via antagonism of the interactions of angiogenic growth factors and their receptors with heparin/HS, has entered phase III clinical trial as an anti-tumor agent. ${ }^{11)}$ However, the use of heparin/HS and their derivatives as therapeutic agents against tumor can be limited due to their inhibition of the blood-coagulation cascade. Non-anticoagulant heparins, which can be used at a higher dose, may be developed as drugs for patients with bleeding complications. ${ }^{12)}$

FGF2 is a major inducer of tumor angiogenesis. ${ }^{13)} \mathrm{He}-$ parin/HS and their derivatives are required for FGF signaling at both cell and animal levels. ${ }^{14)}$ The chain length was found to be critical for the bioactivity of heparin/HS. While heparin/HS possessing anticoagulation activity must have a size equal or larger than a pentasaccharide, heparin-derived di-, tri- and tetra-saccharides were found to promote FGF signaling in cell-based assays ${ }^{15,16)}$ which indicate that smaller oligosaccharides can be developed to modulate FGF signaling without affecting coagulation properties of the system.

The sulfation pattern is another important determinant of heparin/HS biological activity. It is emerging that different sulfation patterns modulate different biological activities. Crystallography studies have shown that interactions between FGF, FGFR and heparin are mediated by sulfates and other functional groups such as carboxylate and ring oxygens. ${ }^{17)}$ Similarly, the formation of antithrombin thrombin ·heparin ternary complex largely depends on the hydrogen bonds participated by sulfates. ${ }^{18,19)}$ Moreover, only fully sulfated disaccharide with eight sulfates, but not disaccharides with less than eight sulfates form a ternary complex and promote FGF signaling. ${ }^{20)}$ In contrast, the non-sulfated di- and tri-saccharides mentioned above bind to FGF2 with high affinity ligands and promote FGF signaling through an unknown mechanism. ${ }^{16)}$ Both $\mathrm{N}$ - and $\mathrm{O}$-desulfated heparin have been reported to be non-anticoagulants but remain some other biological activities such as anti-angiogenic activities. ${ }^{8,21-24)}$ Thus, while the anti-coagulant effect and FGF/FGFR/heparin ternary complex formation requires a high level of sulfation, non-sulfated sugars also modulate FGF signalings through an unidentified mechanism.

Indeed, Murphy and his co-workers reported that mono-
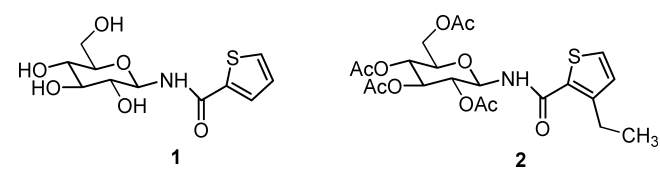

Fig. 1. The Structure of Compounds $\mathbf{1}$ and $\mathbf{2}$ 
saccharide-based glycoconjugates such as compound 1 (Fig. 1) exhibited potent bioactivities in both a FGF2 binding assay and an endothelial cell survival assay. ${ }^{25)}$ Further, they found per- $O$-acetylated glucosamine derivatives such as compound $\mathbf{2}$ possessing significantly improved inhibitory potency to their corresponding polyhydroxylated derivatives. ${ }^{26,27)}$ However, it remains to be demonstrated whether these glycoconjugates reduced endothelial cell proliferation was through their inhibition of FGF signaling. ${ }^{25,26)}$ To understand the molecular mechanism and to discover novel small non-sulfated heparin mimics, we reported the design and synthesis of a series of $\mathrm{N}$-heteroaroyl aminosaccharides derivatives. Their FGF2 signaling modulating abilities were evaluated by using an established FGF2-dependent cell proliferation assay. ${ }^{8)}$

2-Amino-2-deoxy galactose $4^{\prime}$ was prepared from D-galactosamine hydrochloride, according to a reported procedure for the preparation of 2-amino-2-deoxy glucose $\mathbf{3}^{\prime 28)}$ This method involves amino protection by benzaldehyde, which followed by acetylation with $\mathrm{Ac}_{2} \mathrm{O}$. Subsequent removal of the protecting group by acidification with $\mathrm{HCl}$ in acetone gave the compound $\mathbf{4}$ as $\mathrm{HCl}$ salt. Then aminogalactose $\mathbf{4}^{\prime}$ was obtained through treatment of sodium acetate.

Except Compound 24, all other target compounds were obtained by coupling aminosaccharides with diverse heterocyclic acids using 1-(3-dimethylaminopropyl)-3-ethylcarbodiimide hydrochloride/1-hydroxybenzotriazole (EDCI/HOBt) as condensing agent (Chart 1). In this reaction, in order to avoid undesirable deacetylation, the amount of triethylamine required for the conversion of the $\mathrm{HCl}$ salts to their corresponding free amines should be limited to between 1 and 2 eq. But this method was unsuccessful for the synthesis of compound 24. Therefore, compound $\mathbf{2 4}$ was obtained through the reaction of $\mathbf{3}^{\prime}$ with the corresponding acyl chloride derived from 5-methylisoxazole-4-carboxylic acid.

All the compounds were evaluated in a FGF2 and heparindependent cell proliferation assay using FGFR1c expressing $\mathrm{BaF} 3$ cells. Heparin- and FGF-dependent BaF cell proliferation assay was established in $1992 .{ }^{29)} \mathrm{BaF} 3$ cells are a lymphoid cell line, which are dependent on cytokine IL-3 for

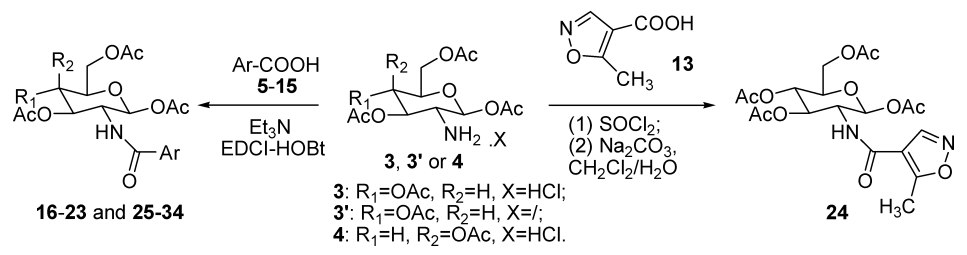

\begin{tabular}{|c|c|c|c|c|c|c|c|}
\hline Compound & $\mathrm{R}_{1}$ & $\mathrm{R}_{2}$ & Ar & Compound & $\mathrm{R}_{1}$ & $\mathrm{R}_{2}$ & $\mathrm{Ar}$ \\
\hline 16 & OAc & $\mathrm{H}$ & & 26 & $\mathrm{H}$ & OAc & \\
\hline 17 & $\mathrm{OAc}$ & $\mathrm{H}$ & & 27 & $\mathrm{H}$ & OAc & \\
\hline 18 & OAc & $\mathrm{H}$ & & 28 & $\mathrm{H}$ & OAc & \\
\hline 19 & OAc & $\mathrm{H}$ & & 29 & $\mathrm{H}$ & OAc & \\
\hline 20 & OAc & $\mathrm{H}$ & & 30 & $\mathrm{H}$ & OAc & \\
\hline 21 & OAc & $\mathrm{H}$ & & 31 & $\mathrm{H}$ & OAc & \\
\hline 22 & OAc & $\mathrm{H}$ & & 32 & $\mathrm{H}$ & OAc & \\
\hline 23 & OAc & $\mathrm{H}$ & & 33 & $\mathrm{H}$ & OAc & \\
\hline 24 & $\mathrm{OAc}$ & $\mathrm{H}$ & & 34 & $\mathrm{H}$ & OAc & \\
\hline 25 & $\mathrm{H}$ & $\mathrm{OAc}$ & & & & & \\
\hline
\end{tabular}

Chart 1. Synthesis of $\mathrm{N}$-Heteroaroyl Aminosaccharide Derivatives (Compounds 16-34) 
growth and have no intrinsic response to FGF. When stably transfected to express FGFR, BaF3 cells die if only FGF or heparin is added to the IL-3 free cell culture media. Proper $\mathrm{BaF} 3$ cells growth can be achieved in the presence of both heparin and FGF. Because BaF3 cells express no endogenous FGF, the background activity in the absence of added FGF is very low regardless of whether the cells express an FGFR, which makes this system idea for testing compounds that can regulate FGF2/FGFR/heparin signaling in this unique cell based system.

We used resazurin to replace previously used ${ }^{3} \mathrm{H}$-thymidine to measure FGF- and GAG-dependent BaF cell proliferation. ${ }^{8)}$ Resazurin is a metabolic indicator dye. In its normal oxidized state it shows very little fluorescence. Once the dye penetrates the cell it becomes reduced to the highly fluorescent resorufin. The rate of resazurin reduction directly correlates with cell numbers and thus reflects overall cell growth induced by heparin, FGFs, and testing compounds.

In this assay, all of the compounds exhibited modulating activities on heparin- and FGF2-dependent BaF3 cell proliferation stimulated by $1 \mu \mathrm{g} / \mathrm{ml}$ heparin and $8 \mathrm{~nm}$ FGF2.

Heparin promoted FGF2/FGFR1c signaling-dependent $\mathrm{BaF}$ cell proliferation as reported previously (Fig. 2A). ${ }^{8)} \mathrm{We}$ tested how these compounds regulated FGF2/FGFR1c/heparin-dependent $\mathrm{BaF}$ cell proliferation in the presence of $1 \mu \mathrm{g} / \mathrm{ml}$ heparin and $8 \mathrm{~nm}$ FGF2 (Fig. 2B). The glucosamine derivatives 16-21 showed more potent inhibitory effects on
BaF3 cells proliferation comparing to galactosamine derivatives 25-34. However, most unexpectedly, while galactosamine derivatives $\mathbf{3 2}, \mathbf{3 3}$, and $\mathbf{3 4}$ showed modest inhibitory effects, their corresponding glucosamine derivatives 22, 23, and 24 were partial agonists in this assay. These results indicated that the carbohydrate moiety is the primary pharmacophore. Given that a change of the configuration of the hydroxyl group at position 4 may either reduce or reverse the bioactivity of these compounds, the binding site of these glycoconjugates may share common characteristics with a receptor which is sensitive to stereo-configuration.

The inhibition of heparin- and FGF2-dependent BaF3 cell proliferation observed in this assay are not likely due to cytotoxic effects for the following reasons: 1) the cytotoxic effects should be more potent when the concentrations of tested compounds are increased. However, most of compounds had higher relative fluorescence unit (RFU) values at $200 \mu \mathrm{g} / \mathrm{ml}$ than those at $40 \mu \mathrm{g} / \mathrm{ml}$ (Fig. 2B); 2) the correlation of higher RFU values and highest concentration $(200 \mu \mathrm{g} / \mathrm{ml})$ for the same compound was consistently observed when repeated in independent $\mathrm{BaF} 3$ cell proliferation assays including testing the compounds in the absence of heparin or performing the same experiments with FGF1 (data not shown); and 3) the inhibition effect observed was dependent on the structures of the tested compounds. Such dependency indicates the observation was not an artifact of the assay.
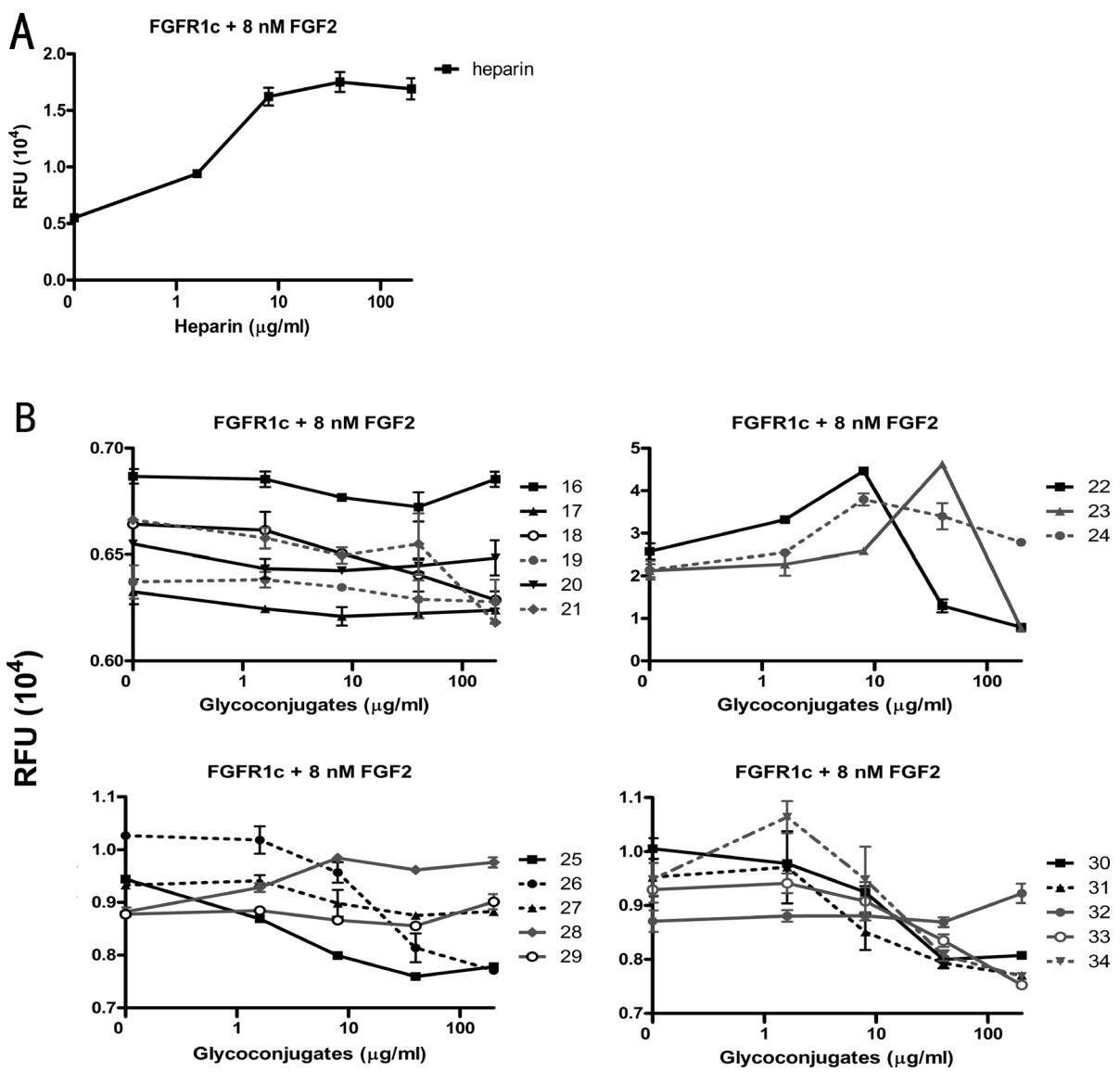

Fig. 2. The Effects of $N$-Heteroaroyl Aminosaccharide Derivatives on BaF3 Cells Proliferation

(A) The effect of heparin on FGF2-dependent BaF3 FGFR1c cell proliferation. (B) The effect of compounds $\mathbf{1 6}-\mathbf{3 4}$ on FGF2-dependent BaF3 FGFR1c cell proliferation (The FGF2 used for testing compounds $\mathbf{2 2}, \mathbf{2 3}$, and $\mathbf{2 4}$ was from a different batch. This FGF2 lot at the same concentration $(8 \mathrm{~nm})$ had higher activities in the presence of $1 \mu \mathrm{g} / \mathrm{ml}$ heparin than the rest). RFU, relative fluorescence unit. 
Because the heparin/HS possessing anticoagulant effects must contain a domain structure with the size larger than pentasaccharide, it is expected that our target compounds are FGF2 signaling modulators but are not anticoagulants. ${ }^{30-33)}$ However, further tests are required to confirm the claim.

In summary, we have described the synthesis of a series of $\mathrm{N}$-heteroaroyl aminosaccharides. This series of compounds modulated FGF2/FGFR1c signaling in a structure-dependent manner. Our studies demonstrated that monosaccharidebased glycoconjugates have effect on FGF2 signaling, which suggests that it may be feasible to search for small non-sulfate heparin mimics to develop novel anti-angiogenic agents. Compounds 16-21 could be considered as lead compounds for development such agents. Since it is still challenging to synthesize a "sequence-pure" polysaccharide, low molecular inhibitors/promoters are more likely to be accepted by the pharmaceutical industry. Further investigation on glycoconjugates will significantly aid the exploration of new potential anti-angiogenic agents. In addition, non-anticoagulant heparin mimics could lead to a better anti-tumor drug by reducing unwanted side effects.

\section{Experimental}

Chemistry Melting points were determined on a RDCSY-I capillary apparatus and were uncorrected. The IR spectra (in $\mathrm{KBr}$ pellets) were recorded on a Nicolet Impact 410 spectrophotometer. The ${ }^{1} \mathrm{H}$ - and ${ }^{13} \mathrm{C}$-NMR spectra were recorded on a Brucker AV-300 or AV-500 NMR spectrometer using tetramethylsilane (TMS) as an internal standard and chemical shifts were given in $\delta$ ppm with TMS. Mass spectra were recorded on an Agilent 1100 series LC/MSD Tarp (SL). The Elemental analysis data were obtained using an Elementar Vario EL III instrument. All solvents were purchased from commercial sources and used as received unless otherwise stated.

General Procedure for Synthesis of Compounds 16-22 and 25-34 Aminosaccharide 3 (or 4) $(0.50 \mathrm{~g}, 1.30 \mathrm{mmol})$ was suspended in anhydrous $\mathrm{CH}_{2} \mathrm{Cl}_{2}(20 \mathrm{ml})$. To this mixture, $\mathrm{Et}_{3} \mathrm{~N}(0.17 \mathrm{ml}, 1.30 \mathrm{mmol})$ was added while cooling in an ice bath, and the resulting solution was stirred at room temperature for $1 \mathrm{~h}$. To this solution, HOBt $(0.175 \mathrm{~g}, 1.30 \mathrm{mmol})$, heterocyclic acids $(1.3 \mathrm{mmol})$, and EDCI $(0.25 \mathrm{~g}, 1.30 \mathrm{mmol})$ were added successively, and the reaction mixture was stirred at room temperature for $24 \mathrm{~h}$. Then the mixture was washed with water $(20 \mathrm{ml} \times 2)$, saturated aqueous $\mathrm{NaHCO}_{3}(20 \mathrm{ml} \times 2)$ and brine $(20 \mathrm{ml} \times 2)$, dried over anhydrous $\mathrm{Na}_{2} \mathrm{SO}_{4}$, filtered and concentrated under reduced pressure. The residue was chromatographed on a silica gel column by use of dichloromethane-methanol $(100: 1-80: 1, \mathrm{v} / \mathrm{v})$ to give compounds $\mathbf{1 6}-\mathbf{2 2}$ and $\mathbf{2 5}-\mathbf{3 4}$

$N$-(1,3,4,6-Tetra- $O$-acetyl-2-deoxy- $\beta$-D-glucopyranosyl)-thiophene-3-carboxamide (16): Isolated yield, $26.9 \%$; mp $230-231^{\circ} \mathrm{C}$ (decomp.). ${ }^{1} \mathrm{H}-\mathrm{NMR}$ $\left(300 \mathrm{MHz}, \mathrm{CDCl}_{3}\right) \delta: 2.00,2.06,2.09,2.11$ (each $3 \mathrm{H}$, each s, each $\mathrm{CH}_{3}$ ), $3.84-3.86(1 \mathrm{H}, \mathrm{m}, \mathrm{H}-5), 4.16(1 \mathrm{H}, \mathrm{dd}, \mathrm{H}-6 \mathrm{~b}, J=1.8,12.3 \mathrm{~Hz}), 4.30(1 \mathrm{H}, \mathrm{dd}$, $\mathrm{H}-6 \mathrm{a}, J=4.5,12.6 \mathrm{~Hz}), 4.46-4.55(1 \mathrm{H}, \mathrm{m}, \mathrm{H}-2), 5.19-5.25(2 \mathrm{H}, \mathrm{m}, \mathrm{H}-$ $3,4), 5.78(1 \mathrm{H}, \mathrm{d}, \mathrm{H}-1, J=8.7 \mathrm{~Hz}), 6.08(1 \mathrm{H}, \mathrm{d}, \mathrm{NH}, J=9.3 \mathrm{~Hz}), 7.33-7.34$ $(2 \mathrm{H}, \mathrm{m}, \mathrm{ArH}), 7.82(1 \mathrm{H}, \mathrm{d}, \mathrm{ArH}, J=1.8 \mathrm{~Hz}) . \mathrm{IR}(\mathrm{KBr}) \mathrm{cm}^{-1}: 3360(\mathrm{NH})$ $2956(\mathrm{CH}), 1749(\mathrm{C}=\mathrm{O}$, ester $), 1653(\mathrm{C}=\mathrm{O}$, amide $), 1536,1511,1254$, $1224,1080,1050,745,602$. MS (electrospray ionization $(\mathrm{ESI})(+) 70 \mathrm{~V}, \mathrm{~m} / \mathrm{z})$ $457.5[\mathrm{M}]^{+} .[\alpha]_{\mathrm{D}}^{25}+45.3\left(c=0.09, \mathrm{CHCl}_{3}\right)$. Anal. Calcd for $\mathrm{C}_{19} \mathrm{H}_{23} \mathrm{NO}_{10} \mathrm{~S}$ : C, 49.89; H, 5.07; N, 3.06. Found: C, 49.89; H, 5.25; N, 2.79

$N$-(1,3,4,6-Tetra- $O$-acetyl-2-deoxy- $\beta$-D-glucopyranosyl)-3-methylthiophene-2-carboxamide (17): Isolated yield, $51.5 \% ; \mathrm{mp} 228-230{ }^{\circ} \mathrm{C}$ (decomp.). ${ }^{1} \mathrm{H}-\mathrm{NMR}\left(300 \mathrm{MHz}, \mathrm{CDCl}_{3}\right) \delta: 2.02,2.06,2.10,2.10$, (each $3 \mathrm{H}$, each s, each $\left.\mathrm{CH}_{3}\right), 2.47\left(3 \mathrm{H}, \mathrm{s}, \mathrm{CH}_{3}\right), 3.86(1 \mathrm{H}, \mathrm{ddd}, \mathrm{H}-5, J=2.4,4.8$, $9.9 \mathrm{~Hz}), 4.15(1 \mathrm{H}, \mathrm{dd}, \mathrm{H}-6 \mathrm{~b}, J=2.1,12.3 \mathrm{~Hz}), 4.30(1 \mathrm{H}, \mathrm{dd}, \mathrm{H}-6 \mathrm{a}, J=4.5$, $12.3 \mathrm{~Hz}), 4.46-4.49(1 \mathrm{H}, \mathrm{m}, \mathrm{H}-2), 5.19(1 \mathrm{H}, \mathrm{t}, \mathrm{H}-4, J=9.6 \mathrm{~Hz}), 5.31(1 \mathrm{H}, \mathrm{t}$, $\mathrm{H}-3, J=9.3 \mathrm{~Hz}), 5.82(1 \mathrm{H}, \mathrm{d}, \mathrm{H}-1, J=8.7 \mathrm{~Hz}), 5.95(1 \mathrm{H}, \mathrm{d}, \mathrm{NH}, J=9.3 \mathrm{~Hz})$, $6.88(1 \mathrm{H}, \mathrm{d}, \mathrm{ArH}, J=5.1 \mathrm{~Hz}), 7.27(1 \mathrm{H}, \mathrm{d}, \mathrm{ArH}, J=4.8 \mathrm{~Hz})$. IR $(\mathrm{KBr}) \mathrm{cm}^{-1}$ : $3365(\mathrm{NH}), 2960,2876(\mathrm{CH}), 1751(\mathrm{C}=\mathrm{O}$, ester $), 1645(\mathrm{C}=\mathrm{O}$, amide), 1512, 1250, 1221, 1076, 1040, 763, 601. MS $(\operatorname{ESI}(+) 70 \mathrm{eV}, \mathrm{m} / \mathrm{z}): 494.2$ $[\mathrm{M}+\mathrm{Na}]^{+}, \mathrm{MS}(\operatorname{ESI}(-) 70 \mathrm{~V}, \mathrm{~m} / \mathrm{z}): 470.1[\mathrm{M}-\mathrm{H}]^{-} \cdot[\alpha]_{\mathrm{D}}^{25}+39.4(c=0.105$ $\mathrm{CHCl}_{3}$ ). Anal. Calcd for $\mathrm{C}_{20} \mathrm{H}_{25} \mathrm{NO}_{10} \mathrm{~S}: \mathrm{C}, 50.95 ; \mathrm{H}, 5.34 ; \mathrm{N}, 2.97$. Found: C, $50.69 ; \mathrm{H}, 5.35 ; \mathrm{N}, 2.99$

$N$-(1,3,4,6-Tetra- $O$-acetyl-2-deoxy- $\beta$-D-glucopyranosyl)-pyridine-4-car- boxamide (18): Isolated yield, $47.7 \%$; mp $220-221^{\circ} \mathrm{C}$ (decomp.). ${ }^{1} \mathrm{H}-\mathrm{NMR}$ $\left(300 \mathrm{MHz}, \mathrm{CDCl}_{3}\right) \delta: 2.02,2.07,2.09,2.12\left(\right.$ each $3 \mathrm{H}$, each s, each $\mathrm{CH}_{3}$ ), 3.86-3.88 (1H, m, H-5), 4.15-4.18 (1H, m, H-6b), $4.31(1 \mathrm{H}, \mathrm{dd}, \mathrm{H}-6 \mathrm{a}$, $J=4.5,12.3 \mathrm{~Hz}), 4.53(1 \mathrm{H}, \mathrm{m}, \mathrm{H}-2), 5.20-5.32(2 \mathrm{H}, \mathrm{m}, \mathrm{H}-3,4), 5.83(1 \mathrm{H}, \mathrm{d}$ $\mathrm{H}-1, J=8.7 \mathrm{~Hz}), 6.57(1 \mathrm{H}, \mathrm{d}, \mathrm{NH}, J=9.3 \mathrm{~Hz}), 7.57(2 \mathrm{H}, \mathrm{d}, \mathrm{ArH}, J=4.5 \mathrm{~Hz})$, $8.76(2 \mathrm{H}, \mathrm{d}, \mathrm{ArH}, J=3.6 \mathrm{~Hz})$. IR ( KBr) cm ${ }^{-1}: 3357(\mathrm{NH}), 2964,2883(\mathrm{CH})$, $1749(\mathrm{C}=\mathrm{O}$, ester $), 1663(\mathrm{C}=\mathrm{O}$, amide $), 1598,1531,1492,1220,1119$, 1079, 1038, 710. MS $(\mathrm{ESI}(+) 70 \mathrm{~V}, \mathrm{~m} / \mathrm{z}): 453.2[\mathrm{M}+\mathrm{H}]^{+} \cdot[\alpha]_{\mathrm{D}}^{25}+24.3$ $\left(c=0.065, \mathrm{CHCl}_{3}\right)$. Anal. Calcd for $\mathrm{C}_{20} \mathrm{H}_{24} \mathrm{~N}_{2} \mathrm{O}_{10}: \mathrm{C}, 53.10 ; \mathrm{H}, 5.35 ; \mathrm{N}, 6.19$. Found: C, 52.97; H, 5.25; N, 5.96

$N$-(1,3,4,6-Tetra- $O$-acetyl-2-deoxy- $\beta$-D-glucopyranosyl)-4-hydroxyl-6methylpyridine-3-carboxamide (19): Isolated yield, $42.3 \% ; \mathrm{mp} 227-229^{\circ} \mathrm{C}$ (decomp.). ${ }^{1} \mathrm{H}-\mathrm{NMR}\left(300 \mathrm{MHz}, \mathrm{DMSO}-d_{6}\right.$ ) $\delta$ : 1.84, 1.97, 1.97, 2.02 (each $3 \mathrm{H}$, each s, each $\left.\mathrm{CH}_{3}\right), 2.24\left(3 \mathrm{H}, \mathrm{s}, \mathrm{CH}_{3}\right), 3.99(1 \mathrm{H}, \mathrm{d}, \mathrm{H}-6 \mathrm{~b}, J=10.8 \mathrm{~Hz})$, $4.18-4.23(3 \mathrm{H}, \mathrm{m}, \mathrm{H}-2, \mathrm{H}-5, \mathrm{H}-6 \mathrm{a}), 4.92(1 \mathrm{H}, \mathrm{t}, \mathrm{H}-4, J=9.6 \mathrm{~Hz}), 5.50(1 \mathrm{H}$, t, H-3, $J=9.9 \mathrm{~Hz}), 6.07(1 \mathrm{H}, \mathrm{d}, \mathrm{H}-1, J=8.7 \mathrm{~Hz}), 6.22(1 \mathrm{H}, \mathrm{s}, \mathrm{ArH}), 8.29(1 \mathrm{H}$, d, ArH, $J=6.3 \mathrm{~Hz}), 10.49(1 \mathrm{H}, \mathrm{d}, \mathrm{NH}, J=9.0 \mathrm{~Hz}), 12.16(1 \mathrm{H}, \mathrm{br}$ s, OH). IR $(\mathrm{KBr}) \mathrm{cm}^{-1}: 3468(\mathrm{OH}), 2950(\mathrm{CH}), 1754(\mathrm{C}=\mathrm{O}$, ester $), 1672(\mathrm{C}=\mathrm{O}$, amide), 1499, 1224, 1082, 1039, 709. MS (ESI $(-) 70 \mathrm{~V}, \mathrm{~m} / \mathrm{z}): 481.2$ $[\mathrm{M}-\mathrm{H}]^{-} \cdot[\alpha]_{\mathrm{D}}^{25}+23.2\left(c=0.185, \mathrm{CHCl}_{3}\right)$. Anal. Calcd for $\mathrm{C}_{21} \mathrm{H}_{26} \mathrm{~N}_{2} \mathrm{O}_{11}: \mathrm{C}$, $52.28 ; \mathrm{H}, 5.43 ; \mathrm{N}, 5.81$. Found: C, 52.24; H, 5.50; N, 5.57.

$N$-(1,3,4,6-Tetra- $O$-acetyl-2-deoxy- $\beta$-D-glucopyranosyl)-4-hydroxyl-5nitro-6-methylpyridine-3-carboxamide (20): Isolated yield, 37.3\%; $\mathrm{mp}$ $240-241^{\circ} \mathrm{C}$ (decomp.). ${ }^{1} \mathrm{H}-\mathrm{NMR}$ (300 MHz, DMSO- $\left.d_{6}\right) \delta: 1.86,1.98$, 1.99, 2.02 (each $3 \mathrm{H}$, each s, each $\left.\mathrm{CH}_{3}\right), 2.35\left(3 \mathrm{H}, \mathrm{s}\right.$, aromatic $\left.\mathrm{CH}_{3}\right), 4.00$ $(1 \mathrm{H}, \mathrm{dd}, \mathrm{H}-6 \mathrm{~b}, J=1.5,12.3 \mathrm{~Hz}), 4.09(1 \mathrm{H}$, ddd, H-5, $J=1.5,3.9,9.9 \mathrm{~Hz})$, $4.22-4.31(2 \mathrm{H}, \mathrm{m}, \mathrm{H}-6 \mathrm{a}, \mathrm{H}-2), 4.93(1 \mathrm{H}, \mathrm{t}, \mathrm{H}-4, J=9.6 \mathrm{~Hz}), 5.54(1 \mathrm{H}, \mathrm{t}, \mathrm{H}-$ $3, J=9.9 \mathrm{~Hz}), 6.09(1 \mathrm{H}, \mathrm{d}, \mathrm{H}-1, J=8.7 \mathrm{~Hz}), 8.46(1 \mathrm{H}, \mathrm{s}, \mathrm{ArH}), 9.72(1 \mathrm{H}, \mathrm{d}$, $\mathrm{NH}, J=9.6 \mathrm{~Hz}), 13.03(1 \mathrm{H}, \mathrm{s}, \mathrm{OH})$. IR $(\mathrm{KBr}) \mathrm{cm}^{-1}: 3453(\mathrm{OH}), 3252(\mathrm{NH})$ $2953(\mathrm{CH}), 1753(\mathrm{C}=\mathrm{O}$, ester $), 1680(\mathrm{C}=\mathrm{O}$, amide $), 1536,1227,1076$, 1039, 585. MS $(\operatorname{ESI}(-) 70 \mathrm{~V}, m / z): 526.2[\mathrm{M}-\mathrm{H}]^{-} .[\alpha]_{\mathrm{D}}^{25}+50.4(c=0.10$, $\mathrm{CHCl}_{3}$ ). Anal. Calcd for $\mathrm{C}_{21} \mathrm{H}_{25} \mathrm{~N}_{3} \mathrm{O}_{13}: \mathrm{C}, 47.82 ; \mathrm{H}, 4.78 ; \mathrm{N}, 7.97$. Found: $\mathrm{C}$, $47.74 ; \mathrm{H}, 5.13 ; \mathrm{N}, 7.88$.

$N$-(1,3,4,6-Tetra- $O$-acetyl-2-deoxy- $\beta$-D-glucopyranosyl)-thiazole-4-carboxamide (21): Isolated yield, $56.9 \%$; mp 232-234 ${ }^{\circ} \mathrm{C}$ (decomp.). ${ }^{1} \mathrm{H}-\mathrm{NMR}$ $\left(300 \mathrm{MHz}, \mathrm{CDCl}_{3}\right) \delta: 1.96,2.05,2.06,2.11$ (each $3 \mathrm{H}$, each s, each $\left.\mathrm{CH}_{3}\right)$, $3.88(1 \mathrm{H}, \mathrm{ddd}, \mathrm{H}-5, J=2.1,4.5,9.6 \mathrm{~Hz}), 4.15(1 \mathrm{H}, \mathrm{dd}, \mathrm{H}-6 \mathrm{~b}, J=2.1$, $12.6 \mathrm{~Hz}), 4.33(1 \mathrm{H}, \mathrm{dd}, \mathrm{H}-6 \mathrm{a}, J=4.5,12.6 \mathrm{~Hz}), 4.41-4.47(1 \mathrm{H}, \mathrm{m}, \mathrm{H}-2)$, $5.19(1 \mathrm{H}, \mathrm{t}, \mathrm{H}-4, J=9.6 \mathrm{~Hz}), 5.36(1 \mathrm{H}, \mathrm{t}, \mathrm{H}-3, J=9.3 \mathrm{~Hz}), 5.87(1 \mathrm{H}, \mathrm{d}, \mathrm{H}-1$, $J=8.7 \mathrm{~Hz}), 7.44(1 \mathrm{H}, \mathrm{d}, \mathrm{NH}, J=9.6 \mathrm{~Hz}), 8.18(1 \mathrm{H}, \mathrm{d}, \mathrm{ArH}, J=1.8 \mathrm{~Hz}), 8.75$ $(1 \mathrm{H}, \mathrm{d}, \mathrm{ArH}, J=2.1 \mathrm{~Hz})$. IR (KBr) cm ${ }^{-1}: 3365(\mathrm{NH}), 2963,2872(\mathrm{CH}), 1749$ ( $\mathrm{C}=\mathrm{O}$, ester $), 1660(\mathrm{C}=\mathrm{O}$, amide $), 1544,1490,1231,1072,1048 . \mathrm{MS}$ $(\mathrm{ESI}(-) 70 \mathrm{~V}, \mathrm{~m} / \mathrm{z}): 457.1[\mathrm{M}-\mathrm{H}]^{-} .[\alpha]_{\mathrm{D}}^{25}+43.9\left(c=0.14, \mathrm{CHCl}_{3}\right)$. Anal. Calcd for $\mathrm{C}_{18} \mathrm{H}_{22} \mathrm{~N}_{2} \mathrm{O}_{10} \mathrm{~S}$ : C, 47.16; H, 4.84; N, 6.11. Found: C, 47.10; H, $4.73 ; \mathrm{N}, 6.08$.

$N$-(1,3,4,6-Tetra- $O$-acetyl-2-deoxy- $\beta$-D-glucopyranosyl)-2-chloro-pyridine-3-carboxamide (22): Isolated yield, $26.9 \%$; mp $228-230{ }^{\circ} \mathrm{C}$ (decomp.). ${ }^{1} \mathrm{H}-\mathrm{NMR}\left(300 \mathrm{MHz}, \mathrm{CDCl}_{3}\right) \delta: 2.06,2.06,2.11,2.15$ (each $3 \mathrm{H}$, each s, each $\left.\mathrm{CH}_{3}\right), 3.89(1 \mathrm{H}$, ddd, $\mathrm{H}-5, J=2.1,4.2,9.6 \mathrm{~Hz}), 4.16(1 \mathrm{H}, \mathrm{dd}, \mathrm{H}-$ $6 \mathrm{~b}, J=1.8,12.6 \mathrm{~Hz}), 4.31(1 \mathrm{H}, \mathrm{dd}, \mathrm{H}-6 \mathrm{a}, J=4.5,12.3 \mathrm{~Hz}), 4.43-4.46(1 \mathrm{H}$ $\mathrm{m}, \mathrm{H}-2), 5.19(1 \mathrm{H}, \mathrm{t}, \mathrm{H}-4, J=9.6 \mathrm{~Hz}), 5.34(1 \mathrm{H}, \mathrm{t}, \mathrm{H}-3, J=9.6 \mathrm{~Hz}), 5.89(1 \mathrm{H}$, d, $\mathrm{H}-1, J=8.7 \mathrm{~Hz}), 6.33(1 \mathrm{H}, \mathrm{d}, \mathrm{NH}, J=9.3 \mathrm{~Hz}), 7.34(1 \mathrm{H}, \mathrm{dd}, \mathrm{ArH}, J=4.8$, $7.8 \mathrm{~Hz}), 7.86(1 \mathrm{H}, \mathrm{dd}, \mathrm{ArH}, J=1.8,7.8 \mathrm{~Hz}), 8.47(1 \mathrm{H}, \mathrm{dd}, \mathrm{ArH}, J=1.8$, $4.8 \mathrm{~Hz})$. IR ( $\mathrm{KBr}) \mathrm{cm}^{-1}: 3307(\mathrm{NH}), 2951,2897(\mathrm{CH}), 1745(\mathrm{C}=\mathrm{O}$, ester), $1662(\mathrm{C}=\mathrm{O}$, amide $), 1582,1535,1223,1086,1043,698 . \mathrm{MS}(\mathrm{ESI}(+) 70 \mathrm{~V}$, $m / z): 487.1[\mathrm{M}+\mathrm{H}]^{+}$; $\mathrm{MS}(\operatorname{ESI}(-) 70 \mathrm{~V}, m / z): 485.0[\mathrm{M}-\mathrm{H}]^{-} .[\alpha]_{\mathrm{D}}^{25}+23.2$ $\left(c=0.185, \mathrm{CHCl}_{3}\right)$. Anal. Calcd for $\mathrm{C}_{20} \mathrm{H}_{23} \mathrm{ClN}_{2} \mathrm{O}_{10}: \mathrm{C}, 49.34 ; \mathrm{H}, 4.76 ; \mathrm{N}$, 5.75. Found: $\mathrm{C}, 49.44 ; \mathrm{H}, 4.77 ; \mathrm{N}, 5.66$

$N$-(1,3,4,6-Tetra- $O$-acetyl-2-deoxy- $\beta$-D-galactopyranosyl)-thiophene-2carboxamide (25): Isolated yield, $37.2 \%$; mp $174-175^{\circ} \mathrm{C}$. ${ }^{1} \mathrm{H}-\mathrm{NMR}$ $\left(300 \mathrm{MHz}, \mathrm{CDCl}_{3}\right) \delta: 1.98,2.07,2.11,2.20$ (each $3 \mathrm{H}$, each s, each $\mathrm{CH}_{3}$ ), $4.07-4.21(3 \mathrm{H}, \mathrm{m}, \mathrm{H}-6 \mathrm{a}, \mathrm{H}-6 \mathrm{~b}, \mathrm{H}-5), 4.61-4.71(1 \mathrm{H}, \mathrm{m}, \mathrm{H}-2), 5.20(1 \mathrm{H}$, dd, H-3, $J=3.0,11.4 \mathrm{~Hz}), 5.43(1 \mathrm{H}, \mathrm{d}, \mathrm{H}-4, J=3.0 \mathrm{~Hz}), 5.81(1 \mathrm{H}, \mathrm{d}, \mathrm{H}-1$, $J=8.7 \mathrm{~Hz}), 5.93(1 \mathrm{H}, \mathrm{d}, \mathrm{NH}, J=9.0 \mathrm{~Hz}), 7.07-7.10(1 \mathrm{H}, \mathrm{m}, \mathrm{ArH}), 7.43$ $(1 \mathrm{H}, \mathrm{d}, \mathrm{ArH}, J=3.6 \mathrm{~Hz}), 7.51(1 \mathrm{H}, \mathrm{d}, \mathrm{ArH}, J=4.8 \mathrm{~Hz}) . \mathrm{IR}(\mathrm{KBr}) \mathrm{cm}^{-1}: 3353$ $(\mathrm{NH}), 2961(\mathrm{CH}), 1749(\mathrm{C}=\mathrm{O}$, ester $), 1646(\mathrm{C}=\mathrm{O}$, amide $), 1536,1512$, $1421,1218,1076,1044 . \mathrm{MS}(\operatorname{ESI}(-) 70 \mathrm{~V}, \mathrm{~m} / z): 456.0[\mathrm{M}-\mathrm{H}]^{-} .[\alpha]_{\mathrm{D}}^{25}$ $+21.3\left(c=0.1250, \mathrm{CHCl}_{3}\right)$. Anal. Calcd for $\mathrm{C}_{19} \mathrm{H}_{23} \mathrm{NO}_{10} \mathrm{~S}: \mathrm{C}, 49.89 ; \mathrm{H}, 5.07$; $\mathrm{N}, 3.06$. Found: C, 49.91; H, 5.13; N, 3.11.

$N$-(1,3,4,6-Tetra- $O$-acetyl-2-deoxy- $\beta$-D-galactopyranosyl)-thiophene-3carboxamide (26): Isolated yield, 47.2\%; mp 187-189 ${ }^{\circ} \mathrm{C} .{ }^{1} \mathrm{H}-\mathrm{NMR}$ $\left(300 \mathrm{MHz}, \mathrm{CDCl}_{3}\right) \delta: 1.98,2.06,2.10,2.20$ (each $3 \mathrm{H}$, each s, each $\mathrm{CH}_{3}$ ), $4.04-4.25(3 \mathrm{H}, \mathrm{m}, \mathrm{H}-6 \mathrm{a}, \mathrm{H}-6 \mathrm{~b}, \mathrm{H}-5), 4.62-4.72(1 \mathrm{H}, \mathrm{m}, \mathrm{H}-2), 5.20(1 \mathrm{H}$, dd, H-3, $J=3.0,11.1 \mathrm{~Hz}), 5.43(1 \mathrm{H}, \mathrm{d}, \mathrm{H}-4, J=2.7 \mathrm{~Hz}), 5.81(1 \mathrm{H}, \mathrm{d}, \mathrm{H}-1$, 
$J=9.0 \mathrm{~Hz}), 5.91(1 \mathrm{H}, \mathrm{d}, \mathrm{NH}, J=9.6 \mathrm{~Hz}), 7.32-7.36(2 \mathrm{H}, \mathrm{m}, \mathrm{ArH}), 7.81-$ $7.82(1 \mathrm{H}, \mathrm{m}, \mathrm{ArH}) . \mathrm{IR}(\mathrm{KBr}) \mathrm{cm}^{-1}: 3355(\mathrm{NH}), 2957(\mathrm{CH}), 1749(\mathrm{C}=\mathrm{O}$, ester $), 1650(\mathrm{C}=\mathrm{O}$, amide $), 1537,1511,1432,1231,1083,1044$. MS $(\operatorname{ESI}(-) 70 \mathrm{~V}, m / z): 456.0[\mathrm{M}-\mathrm{H}]^{-} .[\alpha]_{\mathrm{D}}^{25}+32.0\left(c=0.065, \mathrm{CHCl}_{3}\right)$. Anal. Calcd for $\mathrm{C}_{19} \mathrm{H}_{23} \mathrm{NO}_{10} \mathrm{~S}$ : C, 49.89; H, 5.07; N, 3.06. Found: C, 49.95; H, $5.06 ; \mathrm{N}, 2.95$.

$N$-(1,3,4,6-Tetra- $O$-acetyl-2-deoxy- $\beta$-D-galactopyranosyl)-3-methyl-thiophene-2-carboxamide (27): Isolated yield, $35.9 \% ; \mathrm{mp} 179-181{ }^{\circ} \mathrm{C} .{ }^{1} \mathrm{H}$ NMR $\left(300 \mathrm{MHz}, \mathrm{CDCl}_{3}\right) \delta: 2.00,2.06,2.12,2.19$, (each s, each $3 \mathrm{H}$, each $\left.\mathrm{CH}_{3}\right), 2.47\left(3 \mathrm{H}, \mathrm{s}, \mathrm{CH}_{3}\right), 4.04-4.24(3 \mathrm{H}, \mathrm{m}, \mathrm{H}-5, \mathrm{H}-6 \mathrm{a}, \mathrm{H}-6 \mathrm{~b}), 4.57-4.67$ $(1 \mathrm{H}, \mathrm{m}, \mathrm{H}-2), 5.22(1 \mathrm{H}, \mathrm{dd}, \mathrm{H}-3, J=3.3,11.1 \mathrm{~Hz}), 5.42(1 \mathrm{H}, \mathrm{d}, \mathrm{H}-4$ $J=2.7 \mathrm{~Hz}), 5.66(1 \mathrm{H}, \mathrm{d}, \mathrm{NH}, J=9.3 \mathrm{~Hz}), 5.83(1 \mathrm{H}, \mathrm{d}, \mathrm{H}-1, J=8.7 \mathrm{~Hz}), 6.89$ $(1 \mathrm{H}, \mathrm{d}, \mathrm{ArH}, J=5.1 \mathrm{~Hz}), 7.28(1 \mathrm{H}, \mathrm{d}, \mathrm{ArH}, J=5.1 \mathrm{~Hz}) .{ }^{13} \mathrm{C}-\mathrm{NMR}(75 \mathrm{MHz}$ $\left.\mathrm{CDCl}_{3}\right) \delta: 15.60\left(1 \mathrm{C}, \mathrm{CH}_{3}\right), 20.60\left(4 \mathrm{C}\right.$, each $\left.\mathrm{CH}_{3}\right), 20.61,20.67,20.86$, 50.26 (6C, carbohydrate ring carbons), 61.35, 66.57, 70.42, 72.14, 93.17, 127.06 (4C, ArC), 132.19, 142.08, 163.08 (1C, C=O, amide), 169.51 (4C $\mathrm{C}=\mathrm{O}$, ester $), 170.14,170.37,170.69 . \mathrm{IR}(\mathrm{KBr}) \mathrm{cm}^{-1}: 3325(\mathrm{NH}), 2958$ $(\mathrm{CH}), 1743(\mathrm{C}=\mathrm{O}$, ester $), 1646(\mathrm{C}=\mathrm{O}$, amide $), 1553,1522,1438,1229$, 1085, 1040. MS $(\operatorname{ESI}(-) 70 \mathrm{~V}, \mathrm{~m} / \mathrm{z}): 470.0[\mathrm{M}-\mathrm{H}]^{-}$. $[\alpha]_{\mathrm{D}}^{25}+21.2(c=0.10$ $\mathrm{CHCl}_{3}$ ). Anal. Calcd for $\mathrm{C}_{20} \mathrm{H}_{25} \mathrm{NO}_{10} \mathrm{~S}: \mathrm{C}, 50.95 ; \mathrm{H}, 5.34 ; \mathrm{N}, 2.97$. Found: $\mathrm{C}$, $50.86 ; \mathrm{H}, 5.25 ; \mathrm{N}, 2.63$

$N$-(1,3,4,6-Tetra- $O$-acetyl-2-deoxy- $\beta$-D-galactopyranosyl)-pyridine-3-carboxamide (28): Isolated yield, $42.6 \%$; $\mathrm{mp} 154-157^{\circ} \mathrm{C} .{ }^{1} \mathrm{H}-\mathrm{NMR}$ $\left(300 \mathrm{MHz}, \mathrm{CDCl}_{3}\right) \delta: 1.99,2.06,2.11,2.21$ (each $3 \mathrm{H}$, each s, each $\mathrm{CH}_{3}$ ), $4.07-4.23(3 \mathrm{H}, \mathrm{m}, \mathrm{H}-6 \mathrm{a}, \mathrm{H}-6 \mathrm{~b}, \mathrm{H}-5), 4.68-4.78(1 \mathrm{H}, \mathrm{m}, \mathrm{H}-2), 5.27(1 \mathrm{H}$ dd, H-3, J=3.0, $11.1 \mathrm{~Hz}), 5.45(1 \mathrm{H}, \mathrm{d}, \mathrm{H}-4, J=3.0 \mathrm{~Hz}), 5.87(1 \mathrm{H}, \mathrm{d}, \mathrm{H}-1$, $J=8.7 \mathrm{~Hz}), 6.76(1 \mathrm{H}$, br s, NH), $7.43(1 \mathrm{H}, \mathrm{dd}, \mathrm{ArH}, J=4.8,8.4 \mathrm{~Hz}), 8.10$ $(1 \mathrm{H}, \mathrm{d}, \mathrm{ArH}, J=8.1 \mathrm{~Hz}), 8.75(1 \mathrm{H}, \mathrm{d}, \mathrm{ArH}, J=3.9 \mathrm{~Hz}), 8.96(1 \mathrm{H}, \mathrm{s}, \mathrm{ArH})$. IR $(\mathrm{KBr}) \mathrm{cm}^{-1}: 3366(\mathrm{NH}), 2961(\mathrm{CH}), 1747(\mathrm{C}=\mathrm{O}$, ester $), 1657(\mathrm{C}=\mathrm{O}$ amide), 1529, 1529, 1420, 1219, 1081, 1044. MS (ESI $(+) 70 \mathrm{~V}, \mathrm{~m} / \mathrm{z}): 453.1$ $[\mathrm{M}+\mathrm{H}]^{+} .[\alpha]_{\mathrm{D}}^{25}+24.1\left(c=0.19, \mathrm{CHCl}_{3}\right)$. Anal. Calcd for $\mathrm{C}_{20} \mathrm{H}_{24} \mathrm{~N}_{2} \mathrm{O}_{10}: \mathrm{C}$, $53.10 ; \mathrm{H}, 5.35 ; \mathrm{N}, 6.19$. Found: C, 52.72; H, 5.14; N, 5.81 .

$N$-(1,3,4,6-Tetra- $O$-acetyl-2-deoxy- $\beta$-D-galactopyranosyl)-pyridine-4-carboxamide (29): Isolated yield, 39.1\%; mp $179-180^{\circ} \mathrm{C} .{ }^{1} \mathrm{H}-\mathrm{NMR}$ $\left(300 \mathrm{MHz}, \mathrm{CDCl}_{3}\right) \delta: 1.99,2.07,2.11,2.21$ (each $3 \mathrm{H}$, each s, each $\left.\mathrm{CH}_{3}\right)$, $4.06-4.25(3 \mathrm{H}, \mathrm{m}, \mathrm{H}-6 \mathrm{a}, \mathrm{H}-6 \mathrm{~b}, \mathrm{H}-5), 4.64-4.74(1 \mathrm{H}, \mathrm{m}, \mathrm{H}-2), 5.25(1 \mathrm{H}$ dd, H-3, $J=3.3,11.4 \mathrm{~Hz}), 5.44(1 \mathrm{H}, \mathrm{d}, \mathrm{H}-4, J=2.7 \mathrm{~Hz}), 5.85(1 \mathrm{H}, \mathrm{d}, \mathrm{H}-1$, $J=8.7 \mathrm{~Hz}), 6.50(1 \mathrm{H}, \mathrm{brs}, \mathrm{NH}), 7.56(2 \mathrm{H}, \mathrm{d}, \mathrm{ArH}, J=5.1 \mathrm{~Hz}), 8.76(2 \mathrm{H}, \mathrm{d}$ $\mathrm{ArH}, J=4.8 \mathrm{~Hz}) . \mathrm{IR}(\mathrm{KBr}) \mathrm{cm}^{-1}: 3363(\mathrm{NH}), 2958(\mathrm{CH}), 1745(\mathrm{C}=\mathrm{O}$, ester), 1663 (C=O, amide), 1533, 1492, 1434, 1226, 1083, 1044. MS $(\mathrm{ESI}(+) 70 \mathrm{~V}, \mathrm{~m} / z): 453.2[\mathrm{M}+\mathrm{H}]^{+} .[\alpha]_{\mathrm{D}}^{25}+25.2\left(c=0.21, \mathrm{CHCl}_{3}\right)$. Anal. Calcd for $\mathrm{C}_{20} \mathrm{H}_{24} \mathrm{~N}_{2} \mathrm{O}_{10}$ : C, 53.10; H, 5.35; N, 6.19. Found: C, 53.10; H, $5.40 ; \mathrm{N}, 6.19$

$N$-(1,3,4,6-Tetra- $O$-acetyl-2-deoxy- $\beta$-D-galactopyranosyl)-6-methyl-5nitro-4-hydroxy-pyridine-3-carboxamide (30): Isolated yield, $41.4 \% ; \mathrm{mp}$ $194-195^{\circ} \mathrm{C}$ (decomp.). ${ }^{1} \mathrm{H}-\mathrm{NMR}\left(300 \mathrm{MHz}, \mathrm{CDCl}_{3}\right) \delta: 2.01,2.05,2.12$, 2.18 (each $3 \mathrm{H}$, each s, each $\left.\mathrm{CH}_{3}\right), 2.49\left(3 \mathrm{H}, \mathrm{s}, \mathrm{CH}_{3}\right), 3.79-3.88(1 \mathrm{H}, \mathrm{m}, \mathrm{H}-$ 2), 4.17-4.18 (3H, m, H-5, H-6a, H-6b), 5.41 (1H, d, H-4, J=3.3 Hz), 6.07 $(1 \mathrm{H}, \mathrm{dd}, \mathrm{H}-3, J=3.3,11.1 \mathrm{~Hz}), 6.40(1 \mathrm{H}, \mathrm{d}, \mathrm{H}-1, J=8.7 \mathrm{~Hz}), 8.76(1 \mathrm{H}, \mathrm{d}$, ArH, $J=6.3 \mathrm{~Hz}), 10.01(1 \mathrm{H}, \mathrm{d}, \mathrm{NH}, J=7.2 \mathrm{~Hz}), 10.77(1 \mathrm{H}, \mathrm{br}$ s, OH). IR $(\mathrm{KBr}) \mathrm{cm}^{-1}: 3480(\mathrm{OH}), 3264(\mathrm{NH}), 2961(\mathrm{CH}), 1751(\mathrm{C}=\mathrm{O}$, ester $), 1679$ $(\mathrm{C}=\mathrm{O}$, amide $), 1538,1434,1370,1221,1074,1041 . \mathrm{MS}(\mathrm{ESI}(-) 70 \mathrm{~V}, \mathrm{~m} / \mathrm{z})$ $526.2[\mathrm{M}-\mathrm{H}]^{-}$. $[\alpha]_{\mathrm{D}}^{25}+22.0 \quad\left(c=0.295, \mathrm{CH}_{3} \mathrm{OH}\right)$. Anal. Calcd for $\mathrm{C}_{21} \mathrm{H}_{25} \mathrm{~N}_{3} \mathrm{O}_{13} \cdot 0.5 \mathrm{H}_{2} \mathrm{O}: \mathrm{C}, 47.02 ; \mathrm{H}, 4.89 ; \mathrm{N}, 7.83$. Found: $\mathrm{C}, 47.14 ; \mathrm{H}, 4.83$ $\mathrm{N}, 7.72$

$N$-(1,3,4,6-Tetra- $O$-acetyl-2-deoxy- $\beta$-D-galactopyranosyl)-thiazole-4-carboxamide (31): Isolated yield, $55.0 \%$; mp $224-226^{\circ} \mathrm{C}$ (decomp.). ${ }^{1} \mathrm{H}-\mathrm{NMR}$ $\left(300 \mathrm{MHz}, \mathrm{CDCl}_{3}\right) \delta: 1.94,2.06,2.08,2.20\left(\right.$ each $3 \mathrm{H}$, each s, each $\left.\mathrm{CH}_{3}\right)$, $4.08-4.24(3 \mathrm{H}, \mathrm{m}, \mathrm{H}-6 \mathrm{a}, \mathrm{H}-6 \mathrm{~b}, \mathrm{H}-5), 4.54-4.64(1 \mathrm{H}, \mathrm{m}, \mathrm{H}-2), 5.20(1 \mathrm{H}$ dd, H-3, $J=3.3,11.1 \mathrm{~Hz}), 5.44(1 \mathrm{H}, \mathrm{d}, \mathrm{H}-4, J=2.7 \mathrm{~Hz}), 5.88(1 \mathrm{H}, \mathrm{d}, \mathrm{H}-1$ $J=8.7 \mathrm{~Hz}), 7.32(1 \mathrm{H}, \mathrm{d}, \mathrm{NH}, J=9.6 \mathrm{~Hz}), 8.17(1 \mathrm{H}, \mathrm{d}, \mathrm{ArH}, J=2.1 \mathrm{~Hz}), 8.74$ $(1 \mathrm{H}, \mathrm{d}, \mathrm{ArH}, J=2.1 \mathrm{~Hz}) . \mathrm{IR}(\mathrm{KBr}) \mathrm{cm}^{-1}: 3358(\mathrm{NH}), 2963(\mathrm{CH}), 1750$ $(\mathrm{C}=\mathrm{O}$, ester $), 1662(\mathrm{C}=\mathrm{O}$, amide $), 1544,1489,1371,1226,1073,1044 . \mathrm{MS}$ $(\mathrm{ESI}(-) 70 \mathrm{~V}, \mathrm{~m} / \mathrm{z}): 457.0[\mathrm{M}-\mathrm{H}]^{-} .[\alpha]_{\mathrm{D}}^{25}+19.7\left(c=0.065, \mathrm{CHCl}_{3}\right)$. Anal Calcd for $\mathrm{C}_{18} \mathrm{H}_{22} \mathrm{~N}_{2} \mathrm{O}_{10} \mathrm{~S}$ : C, 47.16; H, 4.84; N, 6.11. Found: C, 47.37; H, $4.87 ; \mathrm{N}, 6.10$

$N$-(1,3,4,6-Tetra- $O$-acetyl-2-deoxy- $\beta$-D-galactopyranosyl)-2-chloro-pyridine-3-carboxamide (32): Isolated yield, $19.1 \%$; mp $147-150{ }^{\circ} \mathrm{C} .{ }^{1} \mathrm{H}-\mathrm{NMR}$ $\left(300 \mathrm{MHz}, \mathrm{CDCl}_{3}\right) \delta: 2.03,2.06,2.16,2.21$ (each $3 \mathrm{H}$, each s, each $\mathrm{CH}_{3}$ ), $4.10-4.20(3 \mathrm{H}, \mathrm{m}, \mathrm{H}-6 \mathrm{a}, \mathrm{H}-6 \mathrm{~b}, \mathrm{H}-5), 4.56-4.65(1 \mathrm{H}, \mathrm{m}, \mathrm{H}-2), 5.28(1 \mathrm{H}$ dd, H-3, $J=3.3,11.4 \mathrm{~Hz}), 5.43(1 \mathrm{H}, \mathrm{d}, \mathrm{H}-4, J=3.3 \mathrm{~Hz}), 5.90(1 \mathrm{H}, \mathrm{d}, \mathrm{H}-1$, $J=8.7 \mathrm{~Hz}), 6.43(1 \mathrm{H}, \mathrm{d}, \mathrm{NH}, J=9.0 \mathrm{~Hz}), 7.31-7.35(1 \mathrm{H}, \mathrm{m}, \mathrm{ArH}), 7.84$ $(1 \mathrm{H}, \mathrm{dd}, \mathrm{ArH}, J=7.5,1.5 \mathrm{~Hz}), 8.45(1 \mathrm{H}, \mathrm{dd}, \mathrm{ArH}, J=1.8,4.8 \mathrm{~Hz})$. IR $(\mathrm{KBr})$ $\mathrm{cm}^{-1}$ : $3426(\mathrm{NH}), 2923(\mathrm{CH}), 1751(\mathrm{C}=\mathrm{O}$, ester), 1659 (C=O, amide),
1584, 1554, 1402, 1370, 1222, 1078, 1043. MS (ESI(-) $70 \mathrm{~V}, \mathrm{~m} / \mathrm{z}): 485.0$ $[\mathrm{M}-\mathrm{H}]^{-} .[\alpha]_{\mathrm{D}}^{24}+10.5\left(c=0.065, \mathrm{CHCl}_{3}\right)$. Anal. Calcd for $\mathrm{C}_{20} \mathrm{H}_{23} \mathrm{ClN}_{2} \mathrm{O}_{10}$ C, 49.34; H, 4.76; N 5.75. Found: C, 49.04; H, 4.81; N, 5.51.

$N$-(1,3,4,6-Tetra- $O$-acetyl-2-deoxy- $\beta$-D-galactopyranosyl)-5-bromo-pyridine-2-carboxamide (33): Isolated yield, 78.3\%; mp 202-204 ${ }^{\circ} \mathrm{C}$. ${ }^{1} \mathrm{H}-\mathrm{NMR}$ $\left(300 \mathrm{MHz}, \mathrm{CDCl}_{3}\right) \delta: 1.93,2.06,2.11,2.20$, (each $3 \mathrm{H}$, each s, each $\mathrm{CH}_{3}$ ), $4.10-4.21(3 \mathrm{H}, \mathrm{m}, \mathrm{H}-6 \mathrm{a}, \mathrm{H}-6 \mathrm{~b}, \mathrm{H}-5), 4.56-4.63(1 \mathrm{H}, \mathrm{m}, \mathrm{H}-2) 5.30(1 \mathrm{H}$, dd, H-3, $J=3.0,11.1 \mathrm{~Hz}), 5.45(1 \mathrm{H}, \mathrm{d}, \mathrm{H}-4, J=3.0 \mathrm{~Hz}), 5.88(1 \mathrm{H}, \mathrm{d}, \mathrm{H}-1$, $J=9.0 \mathrm{~Hz}), 7.86(1 \mathrm{H}, \mathrm{d}, \mathrm{NH}, J=9.6 \mathrm{~Hz}), 7.96-8.07(2 \mathrm{H}, \mathrm{m}, \mathrm{ArH}), 8.60$ $(1 \mathrm{H}, \mathrm{s}, \mathrm{ArH}) . \mathrm{IR}(\mathrm{KBr}) \mathrm{cm}^{-1}: 3354(\mathrm{NH}), 2969(\mathrm{CH}), 1752(\mathrm{C}=\mathrm{O}$, ester $)$ $1671(\mathrm{C}=\mathrm{O}$, amide $), 1579,1531,1465,1372,1220,1078,1046 . \mathrm{MS}$ $(\mathrm{ESI}(-) 70 \mathrm{~V}, \mathrm{~m} / \mathrm{z}): 528.8[\mathrm{M}-\mathrm{H}]^{-} .[\alpha]_{\mathrm{D}}^{24}+31.4\left(c=0.13, \mathrm{CHCl}_{3}\right)$. Anal. Calcd for $\mathrm{C}_{20} \mathrm{H}_{23} \mathrm{BrN}_{2} \mathrm{O}_{10}$ : C, 45.21; H, 4.36; N, 5.27. Found: C, 45.22; H, $4.47 ; \mathrm{N}, 5.13$

$N$-(1,3,4,6-Tetra- $O$-acetyl-2-deoxy- $\beta$-D-galactopyranosyl)-5-methylisoxazole-4-carboxamide (34): Isolated yield, $50.8 \%$; mp $165-167{ }^{\circ} \mathrm{C} .{ }^{1} \mathrm{H}-\mathrm{NMR}$ $\left(300 \mathrm{MHz}, \mathrm{CDCl}_{3}\right) \delta: 2.00,2.06,2.11,2.20$ (each $3 \mathrm{H}$, each s, each $\mathrm{CH}_{3}$ ), $2.70\left(3 \mathrm{H}, \mathrm{s}, \mathrm{CH}_{3}\right), 4.07-4.20(3 \mathrm{H}, \mathrm{m}, \mathrm{H}-5, \mathrm{H}-6 \mathrm{a}, \mathrm{H}-6 \mathrm{~b}), 4.58-4.68(1 \mathrm{H}$ m, H-2), $5.18(1 \mathrm{H}, \mathrm{dd}, \mathrm{H}-3, J=3.0,11.1 \mathrm{~Hz}), 5.41(1 \mathrm{H}, \mathrm{d}, \mathrm{H}-4, J=2.7 \mathrm{~Hz})$, $5.79(1 \mathrm{H}, \mathrm{d}, \mathrm{H}-1, J=8.7 \mathrm{~Hz}), 6.41(1 \mathrm{H}, \mathrm{d}, \mathrm{NH}, J=9.6 \mathrm{~Hz}), 8.35(1 \mathrm{H}, \mathrm{s}, \mathrm{ArH})$. IR $(\mathrm{KBr}) \mathrm{cm}^{-1}: 3366(\mathrm{NH}), 2979(\mathrm{CH}), 1752(\mathrm{C}=\mathrm{O}$, ester $), 1677(\mathrm{C}=$ $\mathrm{O}$, amide), 1617, 1540, 1484, 1370, 1220, 1042. MS (ESI $(-) 70 \mathrm{~V}, \mathrm{~m} / \mathrm{z})$ $454.9[\mathrm{M}-\mathrm{H}]^{-} .[\alpha]_{\mathrm{D}}^{24}+15.4 \quad\left(c=0.065, \mathrm{CHCl}_{3}\right)$. Anal. Calcd for $\mathrm{C}_{19} \mathrm{H}_{24} \mathrm{~N}_{2} \mathrm{O}_{11} \cdot 0.5 \mathrm{H}_{2} \mathrm{O}: \mathrm{C}, 49.03 ; \mathrm{H}, 5.41 ; \mathrm{N}, 6.02$. Found: C, 49.17; H, 5.39; $\mathrm{N}, 6.02$.

$\boldsymbol{N}$-(1,3,4,6-Tetra- $\boldsymbol{O}$-acetyl-2-deoxy- $\boldsymbol{\beta}$-D-glucopyranosyl)-5-bromo-pyridine-2-carboxamide (23) HOBt $(0.19 \mathrm{~g}, 1.41 \mathrm{mmol})$, 5-bromopicolinic acid $(0.29 \mathrm{~g}, 1.44 \mathrm{mmol})$, and EDCI $(0.28 \mathrm{~g}, 1.46 \mathrm{mmol})$ were added successively into a solution of aminosaccharide $3^{\prime}(0.50 \mathrm{~g}, 1.44 \mathrm{mmol})$ in anhydrous $\mathrm{CH}_{2} \mathrm{Cl}_{2}(20 \mathrm{ml})$ while cooling in an ice bath, and the reaction mixture was stirred at room temperature for $17 \mathrm{~h}$. Then the mixture was washed with water $(20 \mathrm{ml} \times 2)$, saturated aqueous $\mathrm{NaHCO}_{3}(20 \mathrm{ml} \times 2)$ and brine $(20 \mathrm{ml} \times 2)$, dried over anhydrous $\mathrm{Na}_{2} \mathrm{SO}_{4}$, filtered and concentrated under reduced pressure. The residue was chromatographed on a silica gel column by use of petroleum ether-acetic ether $(3: 2-1: 1, \mathrm{v} / \mathrm{v})$ to give compound 23 as a white solid. Isolated yield, $45.8 \%$; mp 202-203 ${ }^{\circ} \mathrm{C} .{ }^{1} \mathrm{H}-\mathrm{NMR}(300 \mathrm{MHz}$, $\left.\mathrm{CDCl}_{3}\right) \delta: 1.94,2.05,2.05,2.11$ (each $3 \mathrm{H}$, each s, each $\left.\mathrm{CH}_{3}\right), 3.89(1 \mathrm{H}$, ddd, $\mathrm{H}-5, J=2.1,4.2,9.6 \mathrm{~Hz}), 4.15(1 \mathrm{H}, \mathrm{dd}, \mathrm{H}-6 \mathrm{~b}, J=2.1,12.3 \mathrm{~Hz}), 4.33(1 \mathrm{H}, \mathrm{dd}$, H-6a, $J=4.5,12.3 \mathrm{~Hz}), 4.42-4.45(1 \mathrm{H}, \mathrm{m}, \mathrm{H}-2), 5.19(1 \mathrm{H}, \mathrm{t}, \mathrm{H}-4$ $J=9.6 \mathrm{~Hz}), 5.38(1 \mathrm{H}, \mathrm{t}, \mathrm{H}-3, J=9.3 \mathrm{~Hz}), 5.89(1 \mathrm{H}, \mathrm{d}, \mathrm{H}-1, J=8.7 \mathrm{~Hz})$, 7.95-7.99 (3H, m, NH, ArH), $8.60(1 \mathrm{H}, \mathrm{d}, \mathrm{ArH}, J=1.8 \mathrm{~Hz}) . \mathrm{IR}(\mathrm{KBr})$ $\mathrm{cm}^{-1}$ : $3366(\mathrm{NH}), 2952(\mathrm{CH}), 1753(\mathrm{C}=\mathrm{O}$, ester $), 1671(\mathrm{C}=\mathrm{O}$, amide), 1525, 1219, 1085, 1041, 855, 693, 600. MS (ESI $(-) 70 \mathrm{~V}, \mathrm{~m} / \mathrm{z}): 528.9$ $[\mathrm{M}-\mathrm{H}]^{-} .[\alpha]_{\mathrm{D}}^{25}+49.7\left(c=0.175, \mathrm{CHCl}_{3}\right) ;$ Anal. Calcd for $\mathrm{C}_{20} \mathrm{H}_{23} \mathrm{BrN}_{2} \mathrm{O}_{10}$ C, 45.21; H, 4.36; N, 5.27. Found: C, 45.46; H, 4.44; N, 5.23

$N$-(1,3,4,6-Tetra- $O$-acetyl-2-deoxy- $\beta$-D-glucopyranosyl)-5-methylisoxazole-4-carboxamide (24) 5-Methylisoxazole-4-carboxylic acid $(0.25 \mathrm{~g}$, $1.97 \mathrm{mmol})$ were suspended in $\mathrm{SOCl}_{2}(1 \mathrm{ml}, 13.8 \mathrm{mmol})$, and refluxed for $4 \mathrm{~h}$. After the completion of the reaction, excess $\mathrm{SOCl}_{2}$ was removed under reduced pressure to give acyl chloride as yellow oil which was used without further purification. The oil was dissolved in $\mathrm{CH}_{2} \mathrm{Cl}_{2}(1.4 \mathrm{mLl}$ and the solution was added into a biphasic mixture of aminosaccharide $\mathbf{3}^{\prime}(0.68 \mathrm{~g}$, $1.97 \mathrm{mmol})$ in anhydrous $\mathrm{CH}_{2} \mathrm{Cl}_{2}(9.6 \mathrm{ml})$ and $\mathrm{Na}_{2} \mathrm{CO}_{3}(0.21 \mathrm{~g}, 1.97 \mathrm{mmol})$ in $\mathrm{H}_{2} \mathrm{O}(9.6 \mathrm{ml})$. The reaction mixture was stirred at room temperature for $12 \mathrm{~h}$. Then the organic layer was removed and the aqueous layer was extracted with $\mathrm{CH}_{2} \mathrm{Cl}_{2}(27 \mathrm{ml} \times 2)$. The combined organic layer was washed saturated aqueous $\mathrm{NaHCO}_{3}(27 \mathrm{ml} \times 2)$ and brine $(27 \mathrm{ml} \times 2)$, dried over anhydrous $\mathrm{Na}_{2} \mathrm{SO}_{4}$, filtered and concentrated under reduced pressure. The residue was chromatographed on a silica gel column by use of petroleum ether-acetic ether $(3: 2, \mathrm{v} / \mathrm{v})$ to give compound $\mathbf{2 4}$ as a yellowish solid. Isolated yield, $54.8 \%$; mp $170-172{ }^{\circ} \mathrm{C} .{ }^{1} \mathrm{H}-\mathrm{NMR}\left(300 \mathrm{MHz}, \mathrm{CDCl}_{3}\right) \delta: 2.02$, 2.07, 2.10, 2.11 (each 3H, each s, each $\left.\mathrm{CH}_{3}\right), 2.69\left(3 \mathrm{H}, \mathrm{s}, \mathrm{CH}_{3}\right), 3.84(1 \mathrm{H}$, ddd, $\mathrm{H}-5, J=2.1,4.5,8.1 \mathrm{~Hz}), 4.16(1 \mathrm{H}, \mathrm{dd}, \mathrm{H}-6 \mathrm{~b}, J=2.4,12.6 \mathrm{~Hz}), 4.29$ $(1 \mathrm{H}, \mathrm{dd}, \mathrm{H}-6 \mathrm{a}, J=4.8,12.6 \mathrm{~Hz}), 4.43-4.47(1 \mathrm{H}, \mathrm{m}, \mathrm{H}-2), 5.19-5.22(2 \mathrm{H}$, m, H-3, H-4), $5.77(1 \mathrm{H}, \mathrm{d}, \mathrm{H}-1, J=8.7 \mathrm{~Hz}), 5.95(1 \mathrm{H}, \mathrm{d}, \mathrm{NH}, J=9.0 \mathrm{~Hz})$ $8.28(1 \mathrm{H}, \mathrm{s}, \mathrm{ArH}) . \mathrm{IR}(\mathrm{KBr}) \mathrm{cm}^{-1}: 3328(\mathrm{NH}), 2957,2891(\mathrm{CH}), 1745$ $(\mathrm{C}=\mathrm{O}$, ester $), 1658(\mathrm{C}=\mathrm{O}$, amide $), 1609,1537,1249,1224,1087,1037$, 936, 593. MS $(\operatorname{ESI}(-) 70 \mathrm{~V}, m / z): 455.0[\mathrm{M}-\mathrm{H}]^{-}$. $[\alpha]_{\mathrm{D}}^{25}+25.6(c=0.075$ $\mathrm{CHCl}_{3}$ ). Anal. Calcd for $\mathrm{C}_{19} \mathrm{H}_{24} \mathrm{~N}_{2} \mathrm{O}_{11}: \mathrm{C}, 50.00 ; \mathrm{H}, 5.30 ; \mathrm{N}$ 6.14. Found: C, $50.08 ; \mathrm{H}, 5.50 ; \mathrm{N}, 5.92$.

Bioassay In brief, 96-well plates were dispersed with compounds 1634 at $0,1.6,8,40$, and $200 \mu \mathrm{g} / \mathrm{ml}$ in cell culture media containing $1 \mu \mathrm{g} / \mathrm{ml}$ heparin (final concentration). BaF3 cells expressing FGFR1c cells (30000 live cells/well) were added to compounds $\mathbf{1 6}-\mathbf{3 4}$. FGF2 was then added to 
each plate at a final concentration of $8 \mathrm{~nm}$. Cells were cultured for $40 \mathrm{~h}$, followed by adding $20 \mu \mathrm{l}$ resazurin $(2 \mathrm{mg} / \mathrm{ml}$ dissolved in water, Cat. \# R7017, Sigma Aldrich, St. Louis, MO, U.S.A.) to the media for $16 \mathrm{~h}$. The fluorescent signal was monitored using $544 \mathrm{~nm}$ excitation wavelength and $595 \mathrm{~nm}$ emission wavelength by Spectramax M2 plate reader (Molecular Devices). The relative fluorescence unit (RFU) generated from the assay was proportional to the number of living cells in each well. RFU represented heparin and target compounds stimulated or inhibited cell proliferation. Data are mean \pm range of duplicates.

Acknowledgements The project is sponsored by the Scientific Research Foundation for the Returned Overseas Chinese Scholars, State Education Ministry, Qing Lan Project of Jiangsu Province, and a research fund from Children's Discovery Institution in St. Louis, Missouri in the U.S.A. We appreciate the support from Center for Instrumental Analysis, China Pharmaceutical University, for structural analysis of all synthesized compounds.

\section{References}

1) Desnoyers L. R., Pai R., Ferrando R. E., Hotzel K., Le T., Ross J., Carano R., D’Souza A., Qing J., Mohtashemi I., Ashkenazi A., French D. M., Oncogene, 27, 85-97 (2008).

2) Pollock P. M., Gartside M. G., Dejeza L. C., Powell M. A., Mallon M. A., Davies H., Mohammadi M., Futreal P. A., Stratton M. R., Trent J. M., Goodfellow P. J., Oncogene, 26, 7158-7162 (2007).

3) Lanske B., Razzaque M. S., Curr. Opin. Nephrol. Hypertens., 16, $311-318$ (2007).

4) Kharitonenkov A., Shanafelt A. B., BioDrugs, 22, 37-44 (2008).

5) Presta M., Dell'Era P., Mitola S., Moroni E., Ronca R., Rusnati M., Cytokine Growth Factor Rev., 16, 159-178 (2005).

6) Ornitz D. M., Bioessays, 22, 108-112 (2000).

7) Wu Z. L., Zhang L., Yabe T., Kuberan B., Beeler D. L., Love A., Rosenberg R. D., J. Biol. Chem., 278, 17121-17129 (2003).

8) McDowell L. M., Frazier B. A., Studelska D. R., Giljum K., Chen J., Liu J., Yu K., Ornitz D. M., Zhang L., J. Biol. Chem., 281, 69246930 (2006).

9) Mousa S. A., Cardiovasc. Drug Rev., 22, 121-134 (2004).

10) Norrby K., APMIS, 114, 79-102 (2006).

11) Ferro V., Dredge K., Liu L., Hammond E., Bytheway I., Li C., Johnstone K., Karoli T., Davis K., Copeman E., Gautam A., Semin. Thromb. Hemost., 33, 557-568 (2007).

12) Kragh M., Loechel F., Int. J. Oncol., 27, 1159-1167 (2005).

13) Cross M. J., Claesson-Welsh L., Trends Pharmacol. Sci., 22, 201-207 (2001).
14) Hassan H. H., Mini Rev. Med. Chem., 7, 1206-1235 (2007).

15) Delehedde M., Lyon M., Gallagher J. T., Rudland P. S., Fernig D. G., Biochem. J., 366, 235-244 (2002).

16) Ornitz D. M., Herr A. B., Nilsson M., Westman J., Svahn C. M., Waksman G., Science, 268, 432-436 (1995).

17) Schlessinger J., Plotnikov A. N., Ibrahimi O. A., Eliseenkova A. V., Yeh B. K., Yayon A., Linhardt R. J., Mohammadi M., Mol. Cell, 6, $743-750(2000)$.

18) Jin L., Abrahams J. P., Skinner R., Petitou M., Pike R. N., Carrell R. W., Proc. Natl. Acad. Sci. U.S.A., 94, 14683-14688 (1997).

19) Li W., Johnson D. J., Esmon C. T., Huntington J. A., Nat. Struct. Mol. Biol., 11, 857-862 (2004).

20) Yeh B. K., Eliseenkova A. V., Plotnikov A. N., Green D., Pinnell J., Polat T., Gritli-Linde A., Linhardt R. J., Mohammadi M., Mol. Cell. Biol., 22, 7184-7192 (2002).

21) Fryer A., Huang Y. C., Rao G., Jacoby D., Mancilla E., Whorton R., Piantadosi C. A., Kennedy T.,Hoidal J., J. Pharmacol. Exp. Ther., 282, 208-219 (1997).

22) Lapierre F., Holme K., Lam L., Tressler R. J., Storm N., Wee J., Stack R. J., Castellot J., Tyrrell D. J., Glycobiology, 6, 355-366 (1996).

23) Lundin L., Larsson H., Kreuger J., Kanda S., Lindahl U., Salmivirta M., Claesson-Welsh L., J. Biol. Chem., 275, 24653-24660 (2000).

24) Purkerson M. L., Tollefsen D. M., Klahr S., J. Clin. Invest., 81, 69-74 (1988).

25) Pitt N., Duane R. M., O’Brien A., Bradley H., Wilson S. J., O’Boyle K. M., Murphy P. V., Carbohydr. Res., 339, 1873-1887 (2004).

26) Rawe S. L., Doyle D., Zaric V., Rozas I., McMahon K., Tosin M., Bunz H. M., Murphy E. P., Km O. B., Murphy P. V., Carbohydr. Res., 341, 1370-1390 (2006).

27) Rawe S. L., Zaric V., O'Boyle K. M., Murphy P. V., Bioorg. Med. Chem. Lett., 16, 1316-1319 (2006).

28) Xu J.-F. F., Z.-J., Ju C.-L., Chin. J. Syn. Chem., 11, 379-433 (2003).

29) Ornitz D. M., Yayon A., Flanagan J. G., Svahn C. M., Levi E., Leder P., Mol. Cell. Biol., 12, 240-247 (1992).

30) Liu J., Shriver Z., Pope R. M., Thorp S. C., Duncan M. B., Copeland R. J., Raska C. S., Yoshida K., Eisenberg R. J., Cohen G., Linhardt R. J., Sasisekharan R., J. Biol. Chem., 277, 33456-33467 (2002).

31) Atha D. H., Lormeau J. C., Petitou M., Rosenberg R. D., Choay J., Biochemistry, 24, 6723-6729 (1985).

32) Maccarana M., Casu B., Lindahl U., J. Biol. Chem., 268, 2389823905 (1993).

33) Petitou M., van Boeckel C. A., Angew. Chem. Int. Ed. Engl., 43, 3118-3133 (2004). 